\title{
Chronic Bilateral Subdural Hematoma Complicated by Bilateral Epidural Hematoma Complicating Ventriculo-peritoneal Shunt
}

Hassan Baallal*, Ali Akhaddar, Miloud Gazzaz and Brahim El Moustarchid

Department of Neurosurgery, Mohammed V Military Teaching Hospital, University of King Mohammed V Souissi, Rabat, Morocco

*Corresponding author: Hassan Baallal, Department of Neurosurgery, Mohammed V Military Teaching Hospital, University of King Mohammed V Souissi, Rabat, Morocco, Tel: +212652304617; E-mail: baallalnch@gmail.com

Rec date: May 13, 2016, 2016; Acc date: Jun 28, 2016; Pub date: Jun 30, 2016

Copyright: ( 2016 Baallal $\mathrm{H}$, et al. This is an open-access article distributed under the terms of the Creative Commons Attribution License, which permits unrestricted use, distribution, and reproduction in any medium, provided the original author and source are credited.

\begin{abstract}
We report the case of a 40-year-old man with ventriculo-peritoneal shunt who presented with chronic subdural hematoma (CSDH). He underwent burr-hole craniostomy with a closed drainage system. A computed tomography scan conducted on postoperative demonstrated a bilateral acute epidural haematoma in the occipital location. Craniotomy and haematoma evacuation were immediately performed. To the best of our knowledge, this is the first reported case of an acute bilateral hematoma after drainage of a chronic bilateral subdural hematoma complicating ventriculo-peritoneal shunt. Although extremely rare, it should be considered as a possible complication.
\end{abstract}

Keywords: Ventriculo-peritoneal shunt; Chronic subdural hematoma; Acute epidural hematoma

\section{Introduction}

Hydrocephalus is a common neurosurgical condition, which can lead to significant morbidity and mortality if left untreated [1,2]. Among the procedures performed for hydrocephalus, cerebrospinal fluid (CSF) diversion with insertion of ventriculo-peritoneal (VP) shunt remains the most popular method in both adult and pediatric patients $[3,4]$.

Although common, these surgical procedures require careful patient selection and technical skill to ensure an adequate level of surgical success and careful surveillance to assess for complications VP shunt complications are common in both pediatric and adult populations, with reported frequency ranging from $45 \%$ to $59 \%$ in different reports $[5,6]$. We report a very exceptional case of chronic bilateral subdural hematoma complicated by bilateral epidural hematoma complicating ventriculo-peritoneal shunt.

\section{Case Report}

We report a case of a 42-year-old man. His medical and surgical histories were unremarkable presenting with an ependymoma of the fourth ventricle associated chronic obstructive hydrocephalus. The patient was operated by Ventriculo-peritoneal (VP) shunt. The immediate postoperative period was uneventful. Four months later he presented with headache.

Neurological examination revealed mild right hemiparesis and laboratory studies, including coagulation function, showed no remarkable abnormalities. A cranial CT scan revealed a hypoodense bilateral chronic subdural hematoma (Figure 1). Under general anesthesia, the drainage of the bilateral haematoma was performed immediately after the procedure with ablation of the ventriculoperitoneal shunt. The patient complained of headache, which rapidly increased over the next hour together with vomiting and altered consciousness. Urgent CT revealed a large acute extradural haematoma on the same side (Figure 2). The haematoma was evacuated through a craniotomy. The patient was discharged after 20 days with no neurological deficit.

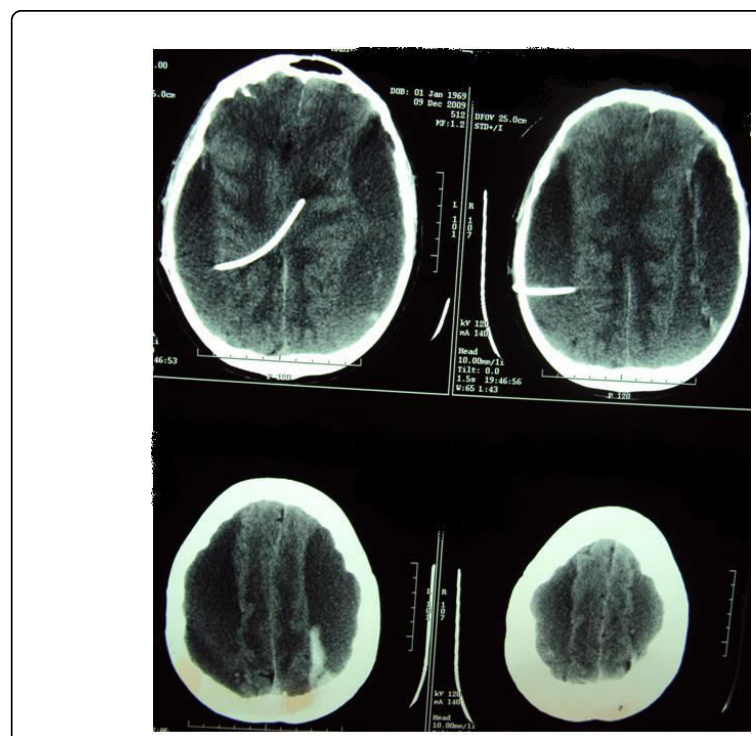

Figure 1: CT scan of the head showing bilateral hypodense chronic subdural hematoma.

\section{Discussion}

Ventriculo-peritoneal shunts are a well-accepted treatment for hydrocephalus and intracranial hypertension. Contemporary surgical series report that approximately a fifth of adult patients experience complications in their first year, with complications occurring about twice as frequently in children [7]. However the chronic bilateral subdural hematoma complicated by bilateral epidural hematoma is a recognised but rare complication following ventriculo-peritoneal shunt [4]. We are not aware of any previously reported cases of this 
association complicating ventriculo-peritoneal shunt in adults. Differential valve shunts systems work on the basis of a differential pressure gradient. The siphon effect of a differential pressure shunt is well known [8-10]. This leads to over drainage of CSF, which predisposes the patients to subdural hematoma, and it is known to have a good prognosis with a relatively simple surgical intervention. However, some postoperative hemorrhage can arise from the craniostomy site and may cause significant morbidity and mortality $[11,12]$.

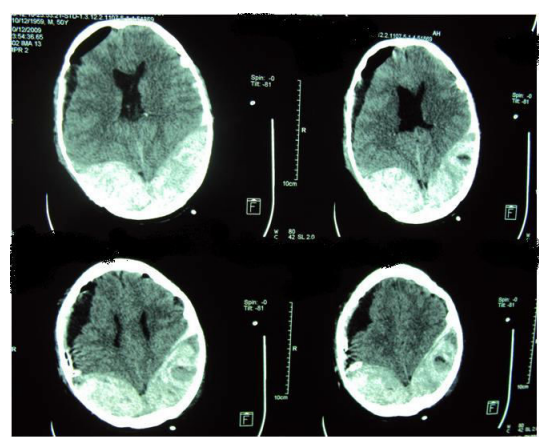

Figure 2: Post-operative CT scan of the head showing bilateral epidural hematoma in occipital location.

The causative factors of the epidural hematomas that happen following chronic bilateral subdural hematoma (CSDH) draining are not explicit. A rapid expansion in the cerebral blood flow with inadequate autoregulation, sudden intra or post-operative stir of the intracranial elements provoke injury to the cerebral vasculature and hemorrhage, with contusion $[13,14]$.

In the present case as well, the pathogenic mechanism underlying the formation of a bilateral epidural haematomas is not only a sudden change in pressure between epidural and subdural space but also excessive detachment of the dura mater.

The patient's medical and family histories did not indicate any coagulopathies, bleeding diathesis, malignancy or systemic disease.

However, the most important factor, as discussed by several authors [14-16] is damage to the cerebral vasculature (diapedesis through the increased permeability of parenchymal blood vessels), secondary to the rapid perioperative parenchymal shift, and a sudden increase in cerebral blood flow combined with focal disruption of autoregulation and cerebral perfusion immediately after surgical decompression [14].

In our patient, the thick dura was particularly resistant to penetration by a relatively blunt subdural needle and, hence, led to the use of sufficient force to detach the dura matter from the inner surface.

Presumably, the bleeding occurred into this space separated from the inner table and compounded by the lack of tamponade by the now evacuated chronic subdural collection.

\section{Conclusion}

Chronic bilateral subdural hematoma complicated by bilateral epidural hematoma is a very rare complication of ventricular decompression in the treatment of hydrocephalus and invariably occur in children or young adults. It should be considered as a possible complication. Clinicians should suspect its occurrence without delay when a postoperative neurological deterioration is demonstrate.

\section{References}

1. Paulsen AH, Lundar T, Lindegaard KF (2010) Twenty-year outcome in young adults with childhood hydrocephalus: Assessment of surgical outcome, work participation, and health-related quality of life. J Neurosurg Pediatr 6: 527-535.

2. Peacock WJ, Currer TH (1984) Hydrocephalus in childhood. A study of 440 cases. S Afr Med J 66: 323-324.

3. Pudenz RH (1981) The surgical treatment of hydrocephalus-an historical review. Surg Neurol 15: 15-26.

4. Reddy GK, Bollam P, Caldito G, Willis B, Guthikonda B, et al. (2011) Ventriculo-peritoneal shunt complications in hydrocephalus patients with intracranial tumors: An analysis of relevant risk factors. J Neuro oncol 103: 333-342.

5. Crnich CJ, Safdar N, Maki DG (2003) Infections associated with implanted medical devices. Antibiotic and chemotherapy: anti-infective agents and their use in therapy. 8: 575-618.

6. Di Rocco C, Marchese E, Velardi F (1994) A survey of the first complication of newly implanted CSF shunt devices for the treatment of non-tumoral hydrocephalus. Cooperative survey of the 1991-1992, Education Committee of the ISPN. Child's nervous system: ChNS: Official Journal of the International Society. Pediatr Neurosurg 10: 321

7. Wu Y, Green NL, Wrensch MR, Zhao S, Gupta N (2007) Ventriculoperitoneal shunt complications in California: 1990 to 2000. Neurosurgery 61: 557-562.

8. Fox JL, McCullough DC, Green RC (1973) Effect of cerebrospinal fluid shunts on intracranial pressure and on cerebrospinal fluid dynamics. 2. A new technique of pressure measurements: results and concepts. 3. A concept of hydrocephalus. J Neurol Neurosurg Psychiatry 36: 302-312.

9. Gruber R, Jenny P, Herzog B (1984) Experiences with the anti-siphon device (ASD) in shunt therapy of pediatric hydrocephalus. J Neurosurg 61: 156-162.

10. Boschert JM, Krauss JK (2006) Endoscopic third ventriculostomy in the treatment of shunt-related over-drainage: Preliminary experience with a new approach how to render ventricles navigable. Clin Neurol Neurosurg 108: 143-149.

11. Gelabert-González M, Iglesias-Pais M, García-Allut A, Martínez-Rumbo R (2005) Chronic subdural haematoma: surgical treatment and outcome in 1000 cases. Clin Neurol Neurosurg 107: 223-229.

12. N'Dri Oka D, Soro L, Broalet E, Varlet G, Ba Zeze V (2000) Extradural hematoma, a possible complication of surgery on chronic subdural hematoma. Neurochirurgie 46: 575.

13. Panourias IG, Skandalakis PN (2006) Contralateral acute epidural haematoma following evacuation of a chronic subdural haematoma with burr-hole craniostomy and continuous closed system drainage: a rare complication. Clin Neurol Neurosurg 108: 396-399.

14. Akhaddar A, Ajja A, Elmostarchid B, Boucetta M (2008) Combined epidural and intracerebral hematomas after evacuation of bilateral chronic subdural hematoma. Neurochirurgie 54: 728-730.

15. Inao S, Kawai T, Kabeya R, Sugimoto T, Yamamoto M, et al. (2001) Relation between brain displacement and local cerebral blood flow in patients with chronic subdural haematoma. J Neurol Neurosurg Psychiatry 71: 741-746.

16. Yamada T, Tanaka Y, Inui $\mathrm{T}$ (1998) Multiple intracerebral hematomas following evacuation of chronic subdural hematoma: A case report. J Neurosurg 7: 120-124. 